\title{
Metodologia para recomendação e agregação de Objetos de Aprendizagem no padrão SCORM
}

\author{
Methodology for recommendation and aggregation of Learning Objects in SCORM
}

\author{
Daniel Eugênio Neves \\ Pontifícia Universidade Católica de \\ Minas Gerais \\ Mestrado em Informática \\ Rua Walter Ianni, 255, São Gabriel, \\ Belo Horizonte - MG \\ den.net@hotmail.com
}

\author{
Wladmir Cardoso Brandão \\ Pontifícia Universidade Católica de \\ Minas Gerais \\ Mestrado em Informática \\ Rua Walter Ianni, 255, São Gabriel, \\ Belo Horizonte - MG \\ wladmir@pucminas.br
}

\author{
Lucila Ishitani \\ Pontifícia Universidade Católica de \\ Minas Gerais \\ Mestrado em Informática \\ Rua Walter Ianni, 255, São Gabriel, \\ Belo Horizonte - MG \\ lucila@pucminas.br
}

\begin{abstract}
Resumo A partir de um trabalho de revisão da literatura sobre a utilização do padrão Sharable Content Object Reference Model (SCORM) para composição de conteúdos para e-Learning, identificouse que, embora amplamente utilizado, seu modelo de metadados para agregação de conteúdos é complexo e dificil de ser utilizado por educadores, desenvolvedores de conteúdo e designers instrucionais. Particularmente, a identificação de conteúdos relacionados entre si, a partir de grandes repositórios, tem sido alvo de consideráveis esforços por parte de pesquisadores em ciência da computação, no sentido da automatização destes processos. Todavia, abordagens anteriores estenderam ou alteraram os metadados definidos pelo SCORM. Diante disso, são apresentados neste artigo os resultados de uma pesquisa experimental na qual foi proposta $e$ avaliada uma metodologia que emprega ontologias, anotação automática de metadados, recuperação de informação e mineração de textos para recomendação automática e agregação de conteúdos relacionados, utilizando o vocabulário da categoria de metadados relation, conforme definida pelo SCORM, sem a necessidade de extensão desses metadados, de realizar alterações no padrão, ou mesmo de implementações específicas nos Sistemas de Gerenciamento de Aprendizagem (SGA). Foi desenvolvido um protótipo de um sistema computacional que aplica a metodologia proposta sobre uma amostragem de objetos de aprendizagem, gerando os resultados para avaliação de sua eficácia. Os resultados foram analisados e avaliados com o apoio de profissionais da educação, que atuam no desenvolvimento de conteúdos para e-Learning, demonstrando que a metodologia proposta é viável e eficaz, produzindo os resultados esperados.
\end{abstract}

Palavras-Chave: SCORM, agregação automática de conteúdo, recomendação automática de conteúdo, Objetos de Aprendizagem, recuperação de informação, mineração de textos.

\footnotetext{
Abstract From a literature review about the composition of educational content for e-Learning in accordance with SCORM, we noticed that, although widely used, the SCORM metadata model for content aggregation is still complex and difficult to be used by educators, content developers and instructional designers. Particularly, the identification of contents related with each other, in large repositories, has been the focus of considerable efforts by researchers in the field of computing in pursuit of the automation of this process. However, previous approaches have extended or altered the metadata defined by SCORM standard. In this paper, we present experimental results on our proposed methodology which employs ontologies, automatic annotation of metadata, information retrieval and text mining to recommend and aggregate related content, using the relation metadata category as defined by SCORM, without extending these metadata, or changing SCORM, or even developing specific implementations on a Learning Management
} 
System. We developed a computer system prototype which applies the proposed methodology on a sample of learning objects generating results to evaluate its efficacy. The results were analyzed and evaluated with the support of educators, who work on the development of content for e-Learning, demonstrating that the proposed method is feasible and effective to produce the expected results.

Keywords: SCORM, automatic content aggregation, automatic content recommendation, Learning Objects, information retrieval, text mining. 


\section{Introdução}

O padrão denominado Sharable Content Object Reference Model (SCORM) possibilita a publicação de Objetos de Aprendizagem (OAs) na Web, por meio de Sistemas de Gerenciamento de Aprendizagem (SGA). Em suas especificações [1, 2, 3] define um Modelo de Agregação de Conteúdos, que é baseado no IEEE Learning Object Metadata (LOM).

Este trabalho apresentada os resultados de uma pesquisa que se iniciou com uma revisão da literatura para identificar o estado da arte em relação à composição de conteúdo para e-Learning, em conformidade com o SCORM. A partir deste estudo percebeu-se que seu modelo de agregação de conteúdos, apesar de amplamente aplicado, é complexo e difícil de ser utilizado por educadores, desenvolvedores de conteúdo e designers instrucionais, pois pressupõe um processo de anotação dispendioso se realizado a partir de um esforço unicamente humano $[17,18,23]$, o que não obstante resulta em metadados insuficientes, quando não incorretos [8], comprometendo a qualidade dos OAs e limitando a utilização dos recursos oferecidos pelo padrão. Dentre estes, a capacidade de extensão de seu conteúdo principal a partir da indicação de OAs correlatos é um exemplo importante $[15,16]$, enquanto a identificação de conteúdos relacionados a partir de grandes repositórios tem sido foco de consideráveis esforços por parte de pesquisadores no campo das ciências da computação, no sentido de automatizar estes processos. Apesar de a categoria de metadados relation classificar diferentes formas de relação entre OAs, há na documentação do SCORM uma definição de como ela está organizada, mas não há um modelo estabelecido para sua utilização. Nos trabalhos relacionados, esta categoria não foi utilizada diretamente tal como definida no SCORM, mas serviu como base para proposição de metadados que a estendem e que demandam implementações específicas nos SGAs para que possam ser interpretados.

A partir das constatações obtidas durante a revisão da literatura, uma pesquisa experimental foi conduzida no sentido de se propor uma metodologia que emprega ontologias, anotação automática de metadados, técnicas de Recuperação da Informação (RI) e Mineração de Textos (MT) para identificação, recomendação automática e agregação de OAs relacionados. Foi utilizado o vocabulário da categoria relation para identificar relações dos tipos requires e isrequiredby, ispartof e haspart, references e isreferencedby, isbasedon e isbasisfor, sem a necessidade de extensão de seus metadados, alterações no SCORM ou implementações específicas no SGA, diferentemente de outros trabalhos referenciados na literatura. Foi implementado o protótipo de um Sistema de Recomendação e Agregação de Conteúdos Re- lacionados, que aplica a metodologia proposta sobre uma amostragem de OAs, extraída de um repositório de conteúdos organizado para este trabalho, gerando os resultados necessários à avaliação de sua eficácia frente ao problema apresentado. Os resultados obtidos são positivos e foram analisados e avaliados com o apoio de profissionais da pedagogia que atuam no desenvolvimento de conteúdos para e-Learning, por meio da comparação entre os resultados gerados pela execução do protótipo e os resultados gerados por um processo manual de geração e anotação de metadados e indicação de documentos relacionados, realizados sobre a mesma amostragem. Diante disso, conclui-se que a metodologia proposta é viável e eficaz, produzindo os resultados esperados, além de ser aplicável à construção de conteúdos didáticopedagógicos pertencentes a diferentes áreas do conhecimento.

Este trabalho está organizado da seguinte forma: a Seção 2 apresenta uma revisão e breve discussão da literatura; a Seção 3 apresenta e discute a metodologia proposta; a Seção 4 apresenta os testes realizados e os resultados alcançados; a Seção 5 apresenta as conclusões e os trabalhos futuros.

\section{Trabalhos Relacionados}

Em [9], Engelhardt e outros procuraram estabelecer relações existentes entre diversos OAs presentes em um repositório. Utilizaram um conjunto de metadados retirado do LOM, acrescido de outro conjunto por eles elaborado. As relações semânticas entre OAs foram formalizadas por meio de uma ontologia baseada na $O W L$ ontology, aplicável a um conjunto de regras de inferência. Propuseram um processo automático para derivação destas relações a partir de um conjunto de relações iniciais. Por fim, propuseram um conjunto de propriedades de relações adicionais, não contempladas pelo LOM. A partir desta estrutura de classificação, foi estabelecida uma rede semântica para todo o repositório, gerando links entre todos os OAs de modo a expressar as relações identificadas entre eles. As soluções apresentadas foram implementadas em um SGA desenvolvido pelos autores, denominado Hypermidia Learning Objects System (hylOs), utilizando o framework Jena ${ }^{1}$ para processamento da ontologia e das regras de inferência. Esta abordagem permitiu a construção de novas relações em sua rede semântica, a cada OA nela inserido, o que pode auxiliar o aluno na busca de conteúdos. Todavia, ao se pensar em processos que necessitem da definição de uma unidade de aprendizagem, cujo conteúdo seja específico e demande uma ordenação objetiva de conceitos e tópicos pré-estabelecidos com base em um planejamento didático-pedagógico, tal solução pode não ser adequada,

${ }^{1}$ http://jena.apache.org/ 
pois os mecanismos fornecidos podem levar a um acesso muito disperso a um conjunto de variados OAs. Assim como em [16] e [8], em [9] foram utilizados uma extensão ao modelo de metadados definido pelo LOM e um SGA específico.

Por sua vez, Edvardsen e outros [8] desenvolveram um framework para geração de metadados em conformidade com o LOM, a partir de um dado OA, obtendo como resultado um novo OA, porém no formato SCORM. Para isso, utilizaram processos de recuperação de metadados contextuais com base em informações presentes no SGA da universidade onde atuam e em entidades extraídas a partir dos próprios OAs, combinando diferentes abordagens para geração automática de metadados a partir de seus respectivos conteúdos. Também recorreram a informações referentes aos cursos ofertados, presentes em um catálogo mantido pela universidade, de onde foram obtidos os metadados relativos ao contexto específico dos cursos e da própria universidade. Os metadados relativos às informações de publicação de cada OA, por sua vez, foram gerados automaticamente com base nos dados de login do SGA. Todos estes metadados foram, por fim, referenciados por elementos previstos no LOM, porém suas fontes denotam grande dependência de elementos externos aos OAs, assim como da forma como estes dados são apresentados.

Apesar de acreditarem que sua pesquisa apresentou resultados inconclusivos com relação à qualidade dos metadados obtidos a partir dos OAs, os autores concluíram que os SGAs podem ser utilizados não apenas para publicá-los, mas também como fonte do que eles chamaram de metadados contextuais [8], que podem ser utilizados como base para geração de metadados específicos para os OAs. Dessa forma, a utilização de informações advindas de fontes externas aos OAs ofereceu recursos adicionais para recuperação e extração de metadados. Porém, a abordagem proposta pode restringir seu escopo de aplicação, ao depender de um framework desenvolvido para utilizar-se de informações que podem não estar disponíveis em outros sistemas e instituições, fazendo com que o mesmo conjunto de metadados possa não ser obtido em outro contexto, além de demandar um SGA específico.

Roy, Sudeshna e Sujoy [23] também estenderam os metadados previstos no LOM, em sua categoria Educational, e propuseram um método para anotação automática de OAs, disponíveis em repositórios de conteúdo, no intuito de possibilitar aos SGAs a seleção apropriada de material de aprendizagem, além de facilitar o trabalho de desenvolvedores de conteúdo no reaproveitamento destes materiais. Neste sentido, desenvolveram uma ontologia cujos atributos pudessem caracterizar os materiais de aprendizagem de um ponto de vista pedagógico. Esta estrutura compôs sua base de conhecimento de domínio, que foi organizada hierarquicamente em três camadas, denominadas respectivamente por term layer, concept ontology e topic taxonomy. Diversos termos, presentes na primeira camada, foram associados a conjuntos de conceitos que os referenciam, presentes na segunda camada. Estes conceitos, por sua vez, permitiram identificar assuntos relacionados com a camada topic taxono$m y$. Tanto o modelo de ontologia quanto a metodologia, desenvolvidos pelos autores, se apresentam como uma proposta consistente e viável para anotação automática de OAs. Todavia, assim como percebemos em [16], [8] e [9], os autores utilizaram metadados que estendem aqueles previstos no modelo de referência, neste caso, da categoria Educational. Além disso, sua abordagem oferece bons mecanismos que permitem a classificação e recuperação de OAs em repositórios, mas não tem como objetivo o estabelecimento de relações entre eles.

Em [20], foi apresentada uma estratégia semelhante àquela adotada em [23], ao utilizar conjuntos de termos para identificar determinadas entidades representativas em um dado conteúdo. Buscando um sistema de recomendação a partir da interação do usuário em sistemas Web, os autores propuseram um framework para anotação de conteúdos relacionados, em arquivos XHTML, que utiliza serviços de análises de dados não estruturados, tais como UIMA $^{1}$ e Calais ${ }^{2}$. Utilizando estes componentes, o sistema por eles proposto foi capaz de analisar automaticamente um dado conteúdo e identificar determinados termos capazes de descrever certos tipos de "entidades", referentes a pessoas, localizações, empresas, dentre outras. Assim, os relacionamentos entre os conteúdos são descritos por meio de tags semânticas que contêm tais entidades que, por sua vez, podem ser ligadas a serviços correlatos, como no caso de uma entidade do tipo "local" e o serviço do Google Maps. Além disso, foi introduzido um modelo de usuário que fornece dados sobre seus interesses e, a partir deste modelo, são selecionados fragmentos de informação para geração das tags. Esta abordagem se mostra como excelente solução para o que se pode entender como uma máquina de busca para conteúdos relacionados na Web. Porém, o processo de recomendação decorrente de tal abordagem, à semelhança do que ocorre em [9], consiste de uma estratégia interessante para inferir-se relações entre conteúdos, mas pode não oferecer o suporte necessário quando o objetivo for a construção de uma unidade de aprendizagem coesa, cujo conteúdo seja composto de OAs agrupados não apenas por estarem relacionados, mas sim em conformidade com uma estrutura organizacional de cunho didático-pedagógico.

Percebe-se que os problemas levantados em [20],

\footnotetext{
${ }^{1}$ http://www.research.ibm.com/UIMA/

${ }^{2}$ HTTP://opencalais.com
} 
[23], [8] e [16] se referem principalmente à dificuldade de se identificar OAs cujos conteúdos estejam de alguma forma relacionados. Em seu trabalho, Lu e Hisieh [15] propuseram a utilização da categoria relation do SCORM para indicar OAs relacionados a partir de um repositório. Porém, para os autores, as relações descritas por esta categoria são limitadas, pois conseguem descrever apenas relacionamentos orientados pela estrutura do conteúdo, não sendo capazes de estabelecer relações semânticas entre os OAs. Diante disso, conforme exposto pelos autores, novos modelos de relações foram propostos por outros pesquisadores. Com base na análise destes modelos, desenvolveram seu próprio modelo de extensão aos metadados da categoria relation definida no SCORM, obtendo quinze novas relações. Em seguida, a utilidade das mesmas, na medida em que auxiliavam os alunos em sua aprendizagem, foi testada e analisada. Os resultados de seus experimentos, segundo eles, indicaram que as novas relações foram consideradas úteis para a maioria dos alunos que contribuíram com sua pesquisa. Os autores consideram interessante que se desenhe um conjunto comum de metadados, no sentido do trabalho por eles realizado, e que sistemas de autoria possam ser criados com suporte ao novo modelo.

Em [16], foi apresentado o modelo de extensão de metadados, anteriormente elaborado em [15], sendo aplicado de forma efetiva no protótipo de um SGA desenvolvido pelos autores, que apresenta suporte ao seu modelo. Trinta autores de conteúdo utilizaram o sistema, atribuindo, eles próprios, as relações entre os OAs. Em seguida, os mesmos avaliaram se houve ganho de aprendizagem com a utilização desse sistema e se seria possível aplicar mais de uma relação a um mesmo Objeto de Aprendizagem. Como resultado, diversas alterações foram realizadas nos arquivos XML que fazem a agregação do conteúdo, levando à inserção de diferentes elementos e atributos, criados e interpretados especificamente para o modelo de metadados e para o SGA desenvolvidos, respectivamente, em [15] e [16]. Os trabalhos realizados pelos autores propuseram um novo formato de agregação com vistas às relações entre OAs, mas não deixam claro se o protótipo de SGA por eles desenvolvido implementa suporte ao restante dos metadados e modelos definidos no SCORM. Assim, os autores obtiveram um modelo distante do SCORM, tratado por um sistema que não suporta o padrão em si, mas sim um conjunto específico de definições, que não encontrarão suporte em outros SGAs.

Em [18], os autores procuraram realizar a extração automática dos metadados definidos na categoria general, do SCORM, para classificar OAs compostos de artigos científicos. Como alguns destes metadados, segundo eles, estão estreitamente relacionados à estrutura $\mathrm{e}$ seções do documento, como no caso do title e descrip- tion, e outros são avaliados a partir de seu próprio conteúdo, tais como language e coverage, diferentes técnicas foram implementadas, para cada tipo de metadado. Para extração dos metadados considerando-se informações estruturais, foi aplicado um passo de pré-processamento, sobre cada arquivo em PDF, obtendo-se, para cada um, um arquivo XML que separa e estrutura cada seção do documento. Este arquivo resultante foi então submetido a uma estratégia de análise baseada em regras para extração dos devidos metadados. No caso dos metadados a serem extraídos a partir do texto do artigo, foi utilizado o Vector Space Model, como estratégia para o processamento de linguagem natural. Com base nos testes aplicados sobre um conjunto de dezessete artigos científicos, os autores constataram que as técnicas por eles propostas permitiram a correta extração dos metadados, com um bom nível de precisão. Diante disso, propuseram, como trabalhos futuros, a extração de metadados mais complexos, em documentos menos estruturados do que aqueles utilizados por eles.

O trabalho desenvolvido por Hernández e outros [11] resulta em um sistema capaz de auxiliar desenvolvedores de conteúdos na criação de OAs de granularidade fina. Ele é capaz de extraí-los para diferentes áreas do conhecimento, desde que se forneça como entrada diferentes ontologias de domínio. Além disso, utiliza recursos para automatização dos processos a partir do emprego de técnicas de recuperação de informação e anotação automática de metadados. Todavia, a variedade de OAs extraídos pode ser grande ou pequena, dependendo da variedade, tamanho e quantidade dos documentos presentes na fonte de conteúdos fornecida como entrada para o sistema, o que pode resultar em redundância destes OAs, ocasionando, ao final do processo, um baixo aproveitamento de seu conjunto. Além disso, a verificação e seleção dos OAs gerados na saída ficam a cargo do usuário do sistema que, porventura, deseje utilizá-los na composição de um OA de granularidade grossa. Ainda neste sentido, o Looking4LO não oferece recursos que auxiliem o desenvolvedor de conteúdos para eLearning na composição de um conteúdo mais extenso e complexo, como no caso de um curso ou disciplina, que demande a identificação e seleção de OAs relacionados entre si, capazes de oferecer conteúdos complementares e, por vezes sequenciáveis, compondo, em seu conjunto, o conteúdo final.

Em [13], por sua vez, Huynh e Hoang buscaram relacionar artigos científicos, com base nos metadados extraídos a partir de documentos em PDF disponíveis na Web. Com base nestes metadados, segundo os autores, é possível reconhecer e saber em quais documentos um dado artigo é referenciado. Para isso, utilizaram componentes e APIs do framework GATE $^{1}$ para desenvolver

\footnotetext{
${ }^{1}$ http://gate.ac.uk
} 
um sistema que processa as informações de layout dos documentos, utilizando regras construídas com base em modelos e uma ontologia, por eles construída, para artigos relacionados à computação. Como referência para os metadados a serem extraídos, os autores adotaram o Dublin Core Metadata. Os metadados obtidos podem ser utilizados para organizar os documentos em bibliotecas digitais ou para enriquecer a ontologia de domínio até então utilizada. Os autores apontam para o fato de que, em sua abordagem, a criação de regras e modelos é um fator crítico para a acurácia do sistema. Além disso, o levantamento de diversos modelos consiste em uma tarefa trabalhosa, que exige tempo e conhecimento de domínio. Sendo assim, propõem como trabalho futuro combinar sua metodologia atual com a utilização de algoritmos de aprendizagem de máquina, no intuito de aumentar sua acurácia e extrair novos grupos de metadados. Após uma breve apresentação dos principais passos executados por seu algoritmo para extração de metadados, assim como a exibição de alguns exemplos de regras por eles definidas, os autores não deixam claro em seu artigo o modo como os metadados obtidos podem ser utilizados para organização dos documentos em bibliotecas digitais. $\mathrm{O}$ mesmo se pode afirmar com relação à utilização dos metadados para identificação de relações entre diferentes artigos.

Uma estratégia semelhante à de [13] foi utilizada por Guo e Jin [12], ao desenvolverem o sistema denominado SemreX, a partir do framework para extração de metadados discutido em [10]. Trata-se de um sistema P2P para compartilhamento de documentos de textos entre pesquisadores em ciência da computação. Seu sistema implementa um framework baseado em regras para extração de metadados presentes nas citações e referências bibliográficas de artigos científicos em PDF. Os arquivos são convertidos pelo sistema em dois formatos diferentes: um arquivo texto simples e um XML. O arquivo texto contém todo o texto do arquivo fonte, porém sem informações de formatação. O XML, por sua vez, utiliza referências espaciais do documento origem para referenciar os blocos de textos e então, para cada um deles, armazenar os dados de formatação. Para os autores, as informações de formatação auxiliam tanto na identificação do tipo de conteúdo, quanto na extração dos metadados, tornando o processo mais preciso. A partir daí, os autores aplicam algoritmos baseados em regras, com a utilização de bases de conhecimento, para extração dos metadados e subsequente atualização da base de conhecimento utilizada.

As abordagens propostas por [13], [10] e [12] consistem em maneiras eficientes de extração de metadados em artigos científicos. Todavia, exploram os aspectos estruturais dos documentos como uma referência primordial para a estratégia adotada. Tais abordagens po- dem não ser tão eficientes quando se tem um conjunto de documentos heterogêneos, como no caso de conteúdos didático-pedagógicos que, ao comporem OAs, não possuem, necessariamente, uma estrutura padronizada para apresentação de seu conteúdo, como ocorre com os artigos científicos.

Para auxiliar nos processos inerentes à Recuperação da Informação, tais como a Geração e Anotação Automáticas de Metadados e Processamento de Linguagem Natural, há diversas ferramentas e frameworks disponíveis. Em [14] foi apresentada uma avaliação de diferentes abordagens e ferramentas para extração de metadados nos cabeçalhos de artigos científicos. Em [20] foi proposto um framework utilizando os serviços de análise de dados não estruturados, denominados UIMA e Calais. Em [9] foi utilizado o framework Jena. Em [19] foi apresentado um benchmarking de ferramentas de anotação automática de texto, concluindo que o GATE obteve a melhor avaliação geral.

Dentre os estudos levantados, os que mais de perto se relacionam a esta pesquisa são aqueles cujas abordagens foram pautadas no padrão SCORM e que se dedicaram a extrair metadados em OAs com base em seu Modelo de Agregação de Conteúdos. Dentre estes, alguns buscaram, além de extrair os metadados, estabelecer uma relação entre os OAs com base nos metadados definidos pela categoria relation. Porém, acabaram por propor extensões aos metadados, além de SGAs específicos para que estes possam ser aplicados. Este último fator levanta uma questão fundamental com relação ao padrão SCORM e um de seus objetivos primordiais, que é garantir a portabilidade e reutilização de seus pacotes de conteúdos em qualquer SGA que implemente seus modelos. Conforme exposto na documentação oficial do SCORM, um dos motivos que levaram à construção do padrão foi o fato de que, anteriormente, cada SGA, assim como cada desenvolvedor de conteúdos, implementava e utilizava seus próprios mecanismos e esquemas de organização de conteúdo para agregação, sequenciamento, navegação e suporte em tempo de execução, prejudicando o reaproveitamento dos OAs e sua portabilidade entre sistemas de gerenciamento. Diante disso, a elaboração de um conjunto de metadados, que necessitem de uma implementação específica no SGA, constitui-se em uma solução que vai contra uma premissa essencial do próprio padrão, pois reduz a portabilidade e compatibilidade do pacote de conteúdo frente a outros sistemas.

\subsection{Mineração de Textos}

Mineração de dados e mineração de textos constituem-se como importantes áreas de pesquisa relacionadas à recuperação e análise de informação em grandes volumes de dados. A primeira lida com dados estruturados cuja estrutura semântica se encontra organizada, por 
exemplo, em uma base de dados relacional. A segunda, mais recente, lida, por sua vez, com dados textuais, que se caracterizam como não estruturados ou semiestruturados, cuja organização está muito mais próxima da linguagem natural. Segundo [4], o termo mineração de dados se refere a "métodos de análise de dados com o objetivo de encontrar regras e modelos que descrevem as propriedades características dos dados." Para os autores, o crescimento exponencial do volume de dados textuais em formato eletrônico, impulsionado principalmente pela Web, traz este desafio da mineração de dados para o contexto da mineração de textos, no qual se busca uma forma eficiente de recuperar informações relevantes a partir deste tipo de dado, heterogêneo e não estruturado. Os autores destacam algumas características especificas da mineração de textos, tais como a análise de relações entre conceitos e a necessidade de uma etapa de préprocessamento linguístico para extração das características principais do texto em análise. Para eles, dentre os principais objetivos se encontram a busca e recuperação de informação, categorização por classificação supervisionada, sumarização, análise de tendência e análise de associações.

Em [6], os autores desenvolveram um sistema de apoio à pesquisa por documentos jurídicos e legais, utilizando um sistema denominado $\mathrm{CKIP}^{1}$ para realização de uma etapa de pré-processamento dos documentos utilizados. O sistema oferece um serviço remoto para processamento de textos em Chinês, que realiza a segmentação do texto, remoção de stopwords e análise sintática e gramatical dos termos e palavras presentes nos textos. Em seguida, utilizaram dois métodos clássicos para computar o peso de cada um dos termos presentes nos documentos: o cálculo da Frequência do Termo (TF) e o cálculo da Frequência Inversa de Documentos (IDF). Em seguida, foi gerado um ranqueamento dos termos de maior peso, obtendo-se, assim, um conjunto de treinamento. Os resultados destes processos foram submetidos à análise de especialistas e reajustados com base em suas observações. Para realização das consultas por parte dos usuários, os autores utilizaram o método Google Similarity Distance ${ }^{2}$, para transformar os termos da entrada do usuário em termos relacionados aos termos legais obtidos nas etapas anteriores e que compõem sua base de treinamento. Este passo de transformação dos termos permitiu que as pesquisas se tornassem mais amigáveis para o usuário, pois possibilitou que buscas fossem feitas fornecendo-se como entrada termos mais populares e menos específicos do jargão do direito. Segundo os autores, os resultados do testes realizados demonstraram que a metodologia por eles proposta apresentou-se mais

\footnotetext{
${ }^{1}$ On-line Chinese words segmented service. October 1, 2011, from http://ckipsvr.iis.sinica.edu.tw/

${ }^{2}$ http://dl.acm.org/citation.cfm?id=1263333
}

eficiente que a abordagem na qual se utiliza apenas os métodos TF-IDF.

\subsection{Ontologia de Domínio}

Ontologias representam um domínio de interesse, por meio de um conjunto de conceitos a ele relevantes e das relações entre eles, possibilitando seu entendimento de forma compartilhada. Sem a conceituação do conhecimento, não há um vocabulário capaz de representá-lo [26]. Sendo assim, a conceituação presente em uma ontologia fornece uma representação abstrata de uma entidade do mundo real, enquanto sua formalização a torna compreensível para uma máquina, além de permitir o compartilhamento do conhecimento [26]. Conforme a estratégia adotada, a ontologia de domínio cumpre um papel fundamental para a recuperação da informação, estabelecendo as relações existentes entre os diversos termos e conceitos presentes na base conhecimento, que são utilizados para identificação de informações relevantes. A simples identificação de um termo ou conceito no texto de um documento, não significa que se tenha obtido uma informação relevante ao seu conteúdo, pois, para que o seja, é necessário que se tenha como parâmetro a área de conhecimento com a qual o termo em questão precise estar relecionado, o que requer conhecimento do domínio, ou seja, uma ontologia que o represente.

\section{Metodologia para Recomendação de OAs Relacionados}

O fluxograma da Figura 1 apresenta uma visão geral da Metodologia para Recomendação e Agregação de OAs Relacionados, em conformidade com o SCORM, proposta nesta pesquisa. São contempladas três etapas, brevemente descritas a seguir e detalhadas nas seções $3.1,3.2$ e 3.3 respectivamente.

A primeira etapa consiste da recuperação de informações relevantes a cada um dos OAs a serem armazenados no repositório de conteúdos. Sendo assim, a partir de uma base de conhecimento de domínio, um conjunto de OAs é submetido a um processo de anotação automática de metadados, que identifica e anota os termoschave e conceitos relevantes em cada um dos documentos. Em seguida, é realizada uma classificação hierárquica destes termos e conceitos quanto ao seu grau de relevância para o conteúdo de seus respectivos OAs. Por fim, para cada termo ou conceito identificado e classificado como relevante, em cada um dos OAs, são geradas associações com suas classes ontológicas. Ao final destes processos, os OAs, devidamente anotados, são, então, armazenados no repositório.

$\mathrm{Na}$ segunda etapa, é realizada a recomendação automática de conteúdos relacionados, quando os OAs armazenados no repositório podem ser selecionados por um 
usuário e utilizados para composição de um dado conteúdo, que é, então, submetido a um processo de recomendação automática de conteúdos a ele relacionados, a partir dos documentos presentes no repositório. Neste processo, outros OAs são pesquisados, com o objetivo de serem recomendados como conteúdos relacionados àqueles previamente selecionados, sendo que, ao final, os documentos recomendados podem ser mantidos ou excluídos manualmente pelo usuário.

Na terceira e última etapa é realizada a agregação automática de conteúdos onde, unindo-se documentos préselecionados e documentos recomendados, é gerado um pacote de conteúdos no formato SCORM, de acordo com as especificações de seu modelo de agregação de conteúdos.

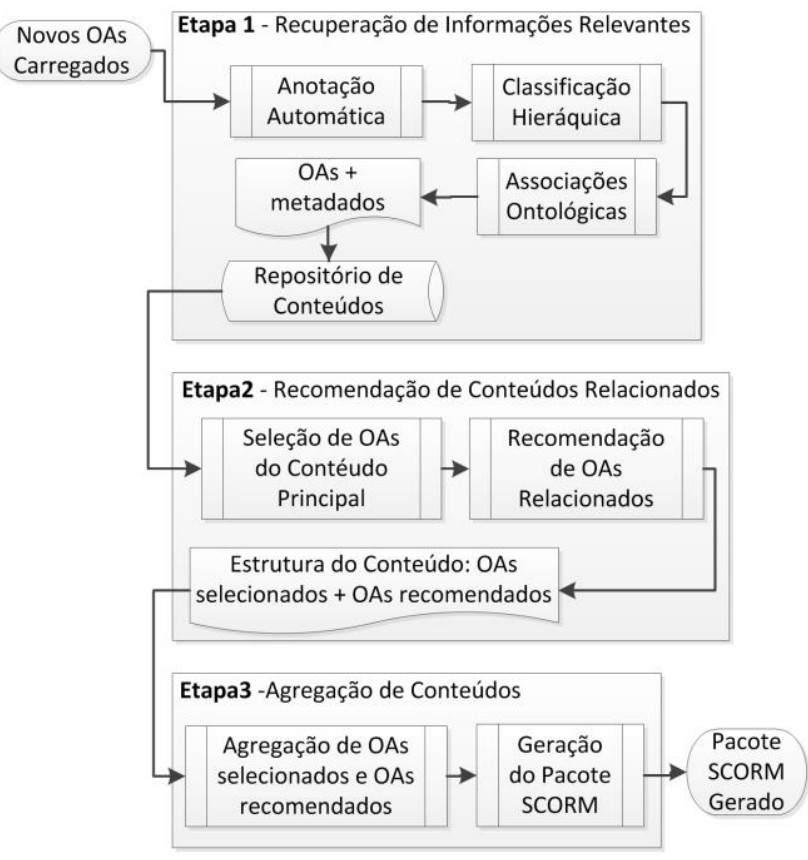

Figura 1 - Metodologia proposta e principais processos

Para os processos contemplados na primeira etapa foram desenvolvidos os módulos AssignerRelevance, para classificação hierárquica dos conceitos relevantes, e o módulo AssociationsBuilder, para geração de associações entre os conceitos relevantes e a ontologia de domínio. Para o processo inicial, de anotação automática de metadados, foi utilizado o plugin ANNIE, do framework GATE. Para a segunda e terceira etapas foi desenvolvido o módulo RecommendationsBuilder, para geração de recomendações de conteúdos relacionados, a partir das associações pré-estabelecidas. A base de conhecimento de domínio aplicada também foi elaborada e desenvolvida como parte deste trabalho de pesquisa.

\subsection{Recuperação de Informações Relevantes}

Esta seção detalha as estratégias e processos utilizados para a recuperação de informações relevantes aos conteúdos dos OAs. Na Seção 3.1.1 é apresentada a base de conhecimento de domínio, contendo o dicionário de termos e a ontologia de domínio. Na Seção 3.1.2 são detalhados os processos de anotação automática de metadados e classificação hierárquica de termos e conceitos relevantes, realizados pelo módulo AssignerRelevance. $\mathrm{Na}$ Seção 3.1.3 é detalhado o processo de associação ontológica dos termos e conceitos relevantes, realizado pelo módulo AssociationsBuilder.

\subsubsection{Base de Conhecimento de Domínio}

Ao se pensar na construção de um determinado curso ou disciplina, os conteúdos dos OAs utilizados, por se tratarem de materiais didático-pedagógicos, estão associados a uma determinada área do conhecimento. Sendo assim, é necessário recuperar informações, a partir de seu conteúdo, que sejam capazes de representá-lo como um todo, sintetizando os principais assuntos nele abordados, e que sejam relevantes à área de conhecimento à qual esteja relacionado. Dessa maneira, em um texto que trate da biografia de um importante compositor da música erudita, por exemplo, não é interessante que se identifique quaisquer nomes de pessoas ou lugares que nele ocorram, mas sim aqueles que estejam relacionados às áreas de conhecimento compreendidas pelo domínio da música erudita, de modo que possam, então, ser posteriormente analisados quanto ao grau de sua relevância para o conteúdo do documento em si. Estes elementos irão compor o conjunto de termos e conceitos mais relevantes ao documento e que o caracterizam quanto ao conteúdo nele presente. Neste contexto, é necessário que se tenha, como referência primordial, um modelo de domínio capaz de caracterizar e representar a área de conhecimento à qual pertencem os OAs, sobre os quais se deseje aplicar estratégias para recuperação da informação que, neste caso, torna-se um processo de recuperação de informações relevantes. Sendo assim, conforme discutido na literatura, o emprego de uma ontologia de domínio é fundamental.

Os conteúdos dos OAs utilizados neste trabalho pertencem ao domínio da área de conhecimento da música erudita. Dessa forma, seus termos e conceitos relevantes são automaticamente anotados a partir de uma base de conhecimento, composta de um dicionário de termos e de uma ontologia de domínio, elaborados e desenvolvidos como parte desta pesquisa. Os elementos presentes no dicionário contemplam a ontologia, enquanto esta permite agrupá-los em classes de conceitos e identifica as ligações e relações entre eles. O dicionário contém 37183 termos e conceitos, distribuídos em 47 arquivos. Estes arquivos recebem nomes que indicam o grupo de 
termos neles contidos e uma extensão de arquivo "lst". Um arquivo principal, que lista todos os demais arquivos e define uma classificação taxonômica, recebe o nome "lists.def".

A ontologia a ser utilizada precisava apresentar uma classificação que contemplasse a área de domínio da música erudita. A única ontologia encontrada foi a OntoMusica. Todavia, esta é bastante restrita, contendo poucas classes de conceitos e com foco na categorização dos mesmos, não permitindo o estabelecimento das relações necessárias para a realização desta pesquisa. Sendo assim, foi proposta uma nova ontologia, contendo 39 classes, distribuídas entre superclasses e subclasses, contendo 31 relações distribuídas entre elas. Suas classes e respectivas relações foram modeladas com a Unified Modeling Language (UML) e construídas utilizando o editor de ontologias do GATE, conforme ilustrado na Figura 2. A proposta de modelagem da ontologia via UML partiu do princípio de que as relações a serem estabelecidas não se apoiariam na estruturação dos documentos, considerando tópicos e subtópicos como foi feito em [15]. Elas seriam estabelecidas entre classes de documentos. Esta caracterização se deve ao fato de que as relações que se busca estabelecer neste trabalho não visam documentos quaisquer, mas documentos que consistem em OAs, entendidos como uma unidade de aprendizagem cujo conteúdo apresenta um determinado assunto e se encerra em si, podendo ou não ser estendido, mas, de todo modo, sendo capaz de ser compreendido por si só, conforme definido em [11].

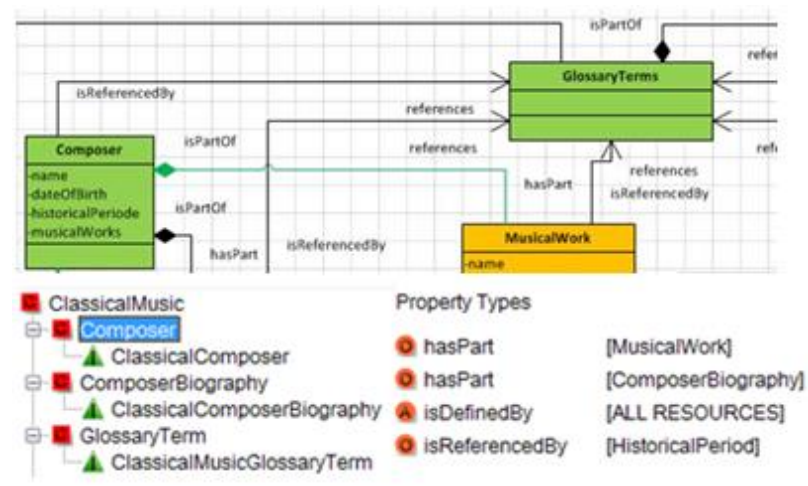

Figura 2 - Recortes da ontologia de domínio

Dessa forma, utilizando um diagrama de classes, foi possível mapear as relações definidas na categoria de metadados relation em relações estabelecidas na UML, por meio de associações, agregações, heranças e especializações. Esta abordagem permitiu conferir um caráter semântico às relações da categoria relation, quando se tem, por exemplo, duas classes denominadas Composer e ComposerBiography, cuja associação se dá por meio de uma agregação, com a qual se estabelece que Compo- ser possui uma relação do tipo hasPart com ComposerBiography e esta, no sentido contrário, estabelece uma relação do tipo isPartOf com Composer. Haja vistas que se o diagrama de classes estivesse modelando um sistema para catalogação de compositores, por exemplo, a relação de agregação com sua biografia estaria coerente. Da mesma forma, observa-se que as relações hasPart e isPartOf podem conter o mesmo significado denotado à agregação da UML. Em outro exemplo, uma obra musical é parte de um compositor, no sentido de agregação em que se um compositor deixa de existir, suas obras também deixam. Logo, trata-se de uma agregação do tipo hasPart e isPartOf, entre as classes Composer e MusicalWork.

O mesmo foi percebido para as demais relações da categoria relation e as respectivas associações na UML. Entre compositor e período histórico, pode-se considerar que um compositor está associado a um período, mas se este período deixa de existir no estudo da história, o mesmo não ocorre com os elementos concretos que estavam a ele associados. Assim, se um compositor estava associado a um dado período histórico, e este deixou de existir, o mesmo pode ser novamente associado a outro período. Dessa forma, adotou-se o entendimento de que um compositor tem como referência um período histórico (isReferencedBy) e um período histórico referencia um compositor (references). Por sua vez, a compreensão da história da música, requer a compreensão de cada um de seus períodos, na medida em que cada período pode ser visto como uma especialização da classe HistoricalPeriod. O mesmo ocorre com gêneros musicais, que requerem o conhecimento de cada um em particular, sendo estes uma especialização da classe dos gêneros musicais. Nestes casos, tem-se relações dos tipos requires e isRequiredBy, no sentido que a classe geral requer classes especializadas e estas são requeridas por ela. No caso de obra musical e gênero musical, temse que, se uma obra musical se caracteriza como uma ópera, então teve sua composição baseada neste gênero musical, que por sua vez lhe serviu de base, em uma associação. Assim, tem-se relações dos tipos isBasisFor e isBasedOn.

As relações recebem os seguintes pesos para associação dos metadados no SCORM: requires/isRequiredBy e isBasisFor/isBasedOn são relações fortes no sentido didático-pedagógico, cujo conteúdo necessita do outro para ser compreendido, logo, os OAs estarão relacionados como pré-requisitos. Por sua vez, references/isReferencedBy e isPartOf /hasPart pressupõem relações de complementação não obrigatória, onde os documentos se complementam mas não dependem uns dos outros para serem compreendidos, logo, os OAs não serão relacionados como pré-requisitos, mas apenas como material complementar. 


\subsubsection{Anotação e Classificação Hierárquica de Termos e Conceitos Relevantes}

Uma vez que novos OAs a serem inseridos no repositório de conteúdos tenham sido carregados pelo sistema a partir de seu repositório original, têm início os processos de geração e anotação automática dos metadados e classificação hierárquica de termos e conceitos relevantes em cada um dos documentos, como parte da etapa de recuperação de informações relevantes.

Para o primeiro processo, o sistema utiliza o plugin ANNIE, enquanto o segundo é realizado pelo módulo AssignerRelevance, a partir da saída gerada pelo ANNIE. Dessa forma, o ANNIE recebe como entrada o corpus contendo os OAs, o dicionário de termos, seu mapeamento para a ontologia e a ontologia de domínio. Sua saída consiste nos OAs contendo termos e conceitos anotados por meio de metadados, que contêm informações quanto à sua classe gramatical e sua classificação ontológica. A Figura 3 ilustra o processo executado pelo ANNIE, conforme configurado para utilização no protótipo de geração das saídas necessárias ao AssignerRelevance.

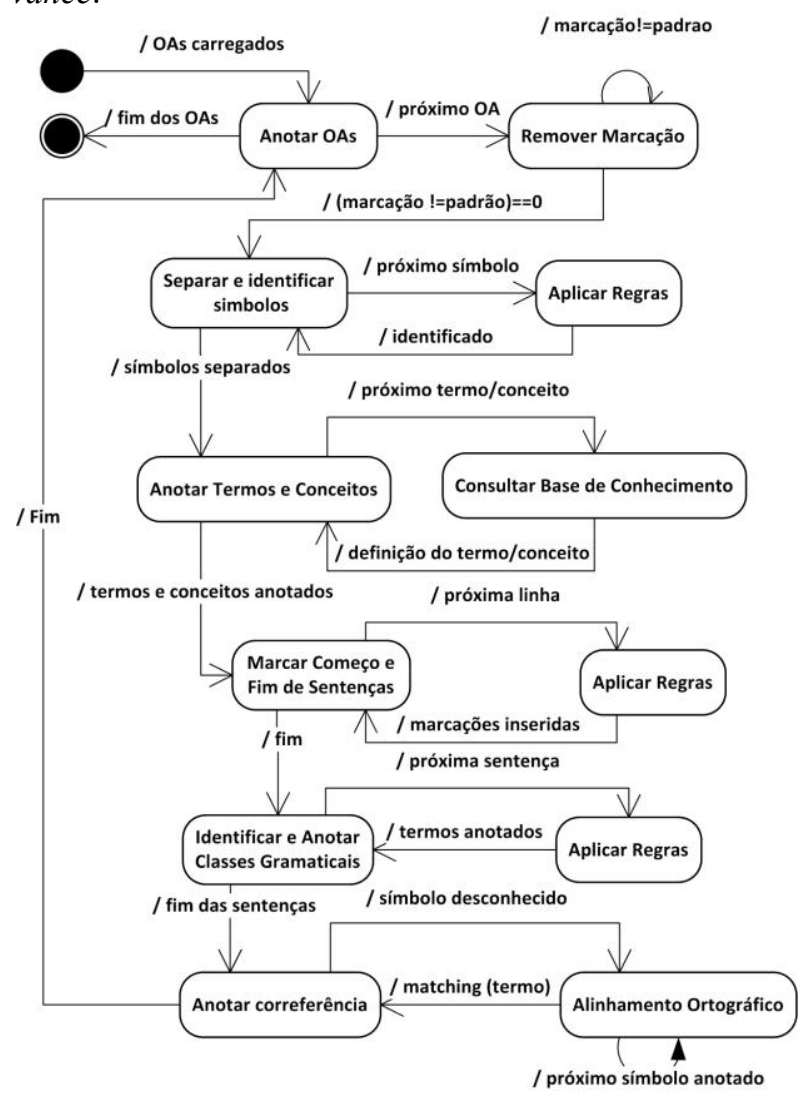

Figura 3 - Geração e Anotação Automáticas de Metadados

O primeiro passo, uma vez iniciada a anotação de um OA, consiste na remoção das marcações que não sejam marcações padrão de formatação e estruturação do texto, além de marcações e anotações inseridas no documento por softwares de autoria e edição, ou quaisquer outras que não pertençam a um conjunto de entrada padrão. Em seguida, os diferentes símbolos presentes no documento são separados e identificados como sendo números, símbolos de pontuação ou palavras. Estes processos utilizam-se da aplicação de diversos conjuntos de regras, lexicons e dados da base de conhecimento. O próximo passo consiste na geração e anotação automática de metadados para identificação dos termos e conceitos relevantes ao conteúdo de cada OA, que são devidamente anotados com seu tipo, posição taxonômica, classificação em relação à ontologia e classe gramatical. Para análise gramatical, cada linha precisa ser analisada, aplicando-se um conjunto de regras no intuito de identificar e separar suas sentenças, para que a classe gramatical de um termo ou conceito possa ser identificada por meio de uma análise de sua posição sintática dentro da sentença. Aqueles termos e conceitos que não forem devidamente identificados são anotados como "desconhecido". Ao final, é necessário buscar correferências para os símbolos que não tenham sido identificados, mas que podem estar relacionados a termos e conceitos importantes para o conteúdo do OA. Para isso, algoritmos de correspondência, ou matching, devem ser aplicados para que cada termo anotado como "desconhecido" possa receber a mesma anotação dada a um termo correspondente, previamente anotado.

Após a anotação dos metadados, é necessário que os termos e conceitos anotados sejam classificados hierarquicamente quanto ao seu nível de relevância, em relação ao conteúdo como um todo. Para isso, o sistema utiliza o módulo AssignerRelevance, que foi implementado de modo a receber como entrada uma lista de OAs e fornecer como saída a mesma lista, porém com novos metadados inseridos em cada OA, para cada termo ou conceito anteriormente anotado, e uma classificação hierárquica de seu conjunto com base no nível de relevância de cada um deles em relação ao texto como um todo. Os novos metadados inseridos pelo AssignerRelevance contêm métricas de relevância para cada um dos termos e conceitos. A partir da análise dos novos metadados gerados, procura-se associar ao termo ou conceito um determinado peso, que pode ser inferido com base em um conjunto de diferentes indicadores de relevância. O cálculo da relevância para cada termo anotado é realizado a partir da seguinte formulação, definida neste trabalho e ilustrada na Figura 4: seja VT um vetor de termos relevantes, $\mathbf{R}_{\mathbf{t i}}$ a relevância de um termo $\mathrm{t}_{\mathbf{i}}, \mathbf{F}_{\mathbf{a b s}(\mathbf{t})}$ a frequência absoluta de um termo $t_{i}, \mathbf{F}_{\text {rel(ti) a frequência }}$ relativa de um termo $t_{i}, \mathbf{T}_{\text {tit }}$ um termo presente no título de um documento $\mathrm{d}_{\mathrm{i}}, \mathbf{T}_{\mathbf{K W}}$ um termo presente nas palavras-chave de um documento $\mathrm{d}_{\mathrm{i}}, \mathbf{T}_{\mathbf{s}}$ um termo que é substantivo, Trel o termo de maior frequência relativa e Sent $_{\text {ti }}$ a sentença onde o termo ocorre. Definem-se as 
seguintes funções: (1) retorna a frequência absoluta do termo $t_{i}$ para o documento $d_{i} ;(2)$ retorna a frequência relativa do termo $t_{i}$ para o documento $d_{i}$, onde $N$ é o número total de termos no documento; (3) recebe um termo $t_{i}$ e a sentença onde ele ocorre e retorna 1.5 caso seja seguido de um substantivo precedido por um verbo de ligação, aumentando sua relevância, ou 1 caso contrário; (4) retorna um fator de relevância de um termo $t_{i}$ para o documento $\mathrm{d}_{\mathrm{i}}$, onde ocorre, a partir de uma avaliação com base na combinação dos parâmetros em $\mathbf{F}_{\text {rel(ti), }}$ $\mathbf{T}_{\text {tit, }} \mathbf{T}_{\mathbf{K W}}$ e $\mathbf{T}_{\mathbf{s}}$; (5) retorna a relevância final de um termo $t_{i}$ para o documento $d_{i}$ onde ocorre, utilizando-se dos valores retornados por (3) e (4) para confirmar o peso de (1). Empregando-se as funções definidas na Figura 4, para cada termo $t_{i}$ em $d_{i}$, calcula-se $\mathbf{F}_{\text {abs(ti) }}=$ FreqAbs $\left(t_{i}, d_{i}\right)$ e Frel(ti) $_{\text {re }}$ FreqRel $\left(t_{i}, d_{i}\right)$. Para todo termo $t_{i}$ em $\mathrm{d}_{\mathrm{i}}$ define-se assim sua relevância $\mathbf{R}_{\mathrm{ti}}$ : $\mathbf{R}_{\mathrm{ti}}=\left[\mathrm{t}_{\mathrm{i}}\right.$, Fun$\left.\operatorname{cRel}\left(\mathrm{t}_{\mathrm{i}}, \mathrm{d}_{\mathrm{i}}\right)\right]$. Se $\mathbf{R}_{\mathbf{t i}}>=0.25, \mathbf{V T} \leftarrow\left[\mathrm{ti}, \mathrm{R}_{\mathrm{ti}}\right]$. A variação entre 0.25 e 2.0 para o retorno de (4) divide, mantém ou dobra o peso inicial atribuído ao termo por (1), gerando assim o seu valor de relevância final.
A Figura 5 ilustra parte de um OA contendo os termos anotados e respectivos metadados gerados até esta etapa. Os metadados são exibidos ao se posicionar o mouse sobre um dos termos marcados no texto do OA. A Figura 6 apresenta parte do arquivo de registro dos metadados gerados para cada OA.

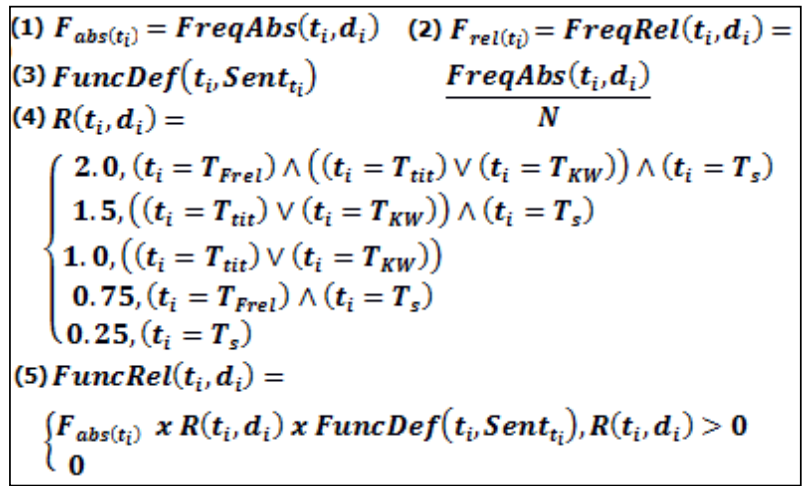

Figura 4 - Funções definidas para o cálculo de relevância Concert aria $\begin{aligned} & \text { \{term_relFequence }=0.012658227848101266, \text { term_absFrequence=2, term_relevance=1.0, term_category=NN, } \\ & \text { associated_term }=\text { aria, minorType }=\text { genre_opera, ontology=file:/C/TestSysRecom/ontology/myontomusic.rdf, class }=0 \text { pera, } \\ & \text { majorType=musical_genre\}Lookup }\end{aligned}$
r of Smetana's The Bartered Bride or in more ambitious works based on

Figura 5 - Termo anotado em um OA e respectivos metadados

\section{$\rightarrow 128$}

AnnotationImpl: id = 2646; Type $=$ Lookup; features $=$ $\{$ term_relFequence $=0.012658227848101266$, term_absFrequence $=2$, term_relevance $=1.0$, term_category $=\mathrm{NN}$, associated_term $=$ aria, minorType = genre_opera, ontology $=$

file:/C:/TestSysRecom/ontology/myontomusic.rdf, class $=$ Opera, majorType $=$ musical_genre $\}$; start=NodeImpl: id=1682; offset $=4111$; end=NodeImpl: id=1683; offset $=4115$

Figura 6 - Parte do arquivo de registros das anotações

\subsubsection{Construindo Associações Ontológicas}

Uma vez cumpridas todas as etapas anteriores, para cada OA presente no repositório, tem-se como resultado um VT, associado a cada documento. O próximo processo a ser executado, como parte da etapa de recuperação de informações relevantes, consiste em se identificar as possíveis relações para cada OA, com base nos elementos de VT. Para isso, o sistema utiliza o módulo AssociationsBuilder, que recebe como entrada a lista de OAs presentes no corpus e fornece como saída as associações possíveis para estes documentos, com base nas relações descritas pela ontologia de domínio, a partir das classes às quais os termos e conceitos relevantes em VT estão associados. Estas associações são inseridas em forma de metadados em cada um dos OAs. Para isso, também foi desenvolvido um parser para a ontologia de domínio, denominado OntologyParser, utilizando recursos da API do GATE, e que é utilizado pelo AssociationsBuilder. A Figura 7 apresenta o processo realizado para construção das associações.

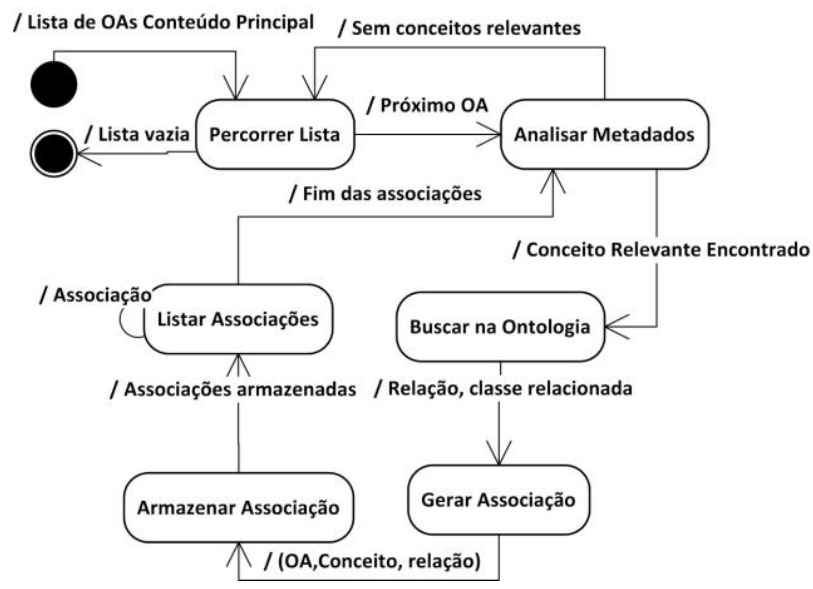

Figura 7 - Construção de Associações

Assim, para cada elemento de VT, seus metadados são analisados e a classe à qual se associam na ontologia, 
anteriormente anotada, é resgatada. A partir dela, o parser retorna a superclasse e as subclasses a ela associadas, assim como as possíveis relações que estabelece com as demais classes, que foram definidas durante a modelagem da ontologia e obedecem ao vocabulário da categoria relation do SCORM: requires e isrequiredby, ispartof e haspart, references e isreferencedby, isbasedon e isbasisfor. Cada associação contém o termo relevante, sua classe, subclasses e as relações, que têm sua classe como domínio e a classe associada como alcance, formando um grafo sobre a ontologia onde as classes são os nós e as relações são as arestas que as conectam. Concluídas as associações, os OAs se encontram com todas as informações necessárias ao processo de recomendação automática de conteúdos relacionados. A Figura 8 ilustra parte do arquivo gerado para verificação das associações anotadas nos respectivos OAs.

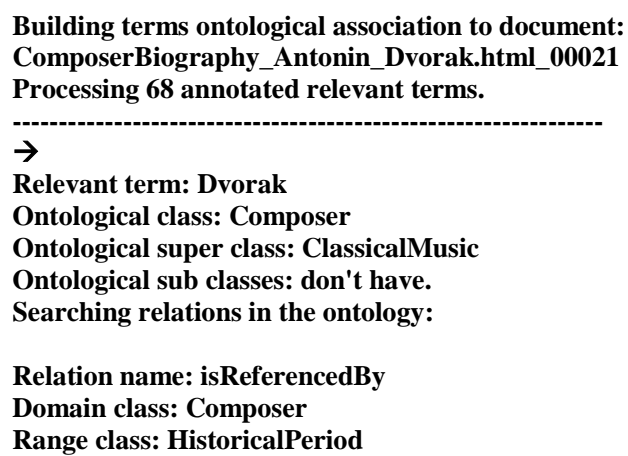

Figura 8 - Parte do arquivo de registros das associações geradas

Após a geração das devidas associações para cada OA, conclui-se a etapa de recuperação de informações relevantes. Assim, os OAs podem, então, ser finalmente persistidos no repositório de conteúdos, juntamente com seus metadados, permanecendo à disposição de autores de conteúdos que queiram utilizá-los para composição de uma unidade de aprendizagem.

\subsection{Recomendação de Conteúdos Relaciona- dos}

Uma vez que se tenha selecionado um conjunto de OAs a partir do repositório, para composição de um dado conteúdo didático-pedagógico, que tenham passado pelas etapas de recuperação de informações relevantes e construção de associações ontológicas, descritos na Seção 3.1 , estes podem ser submetidos ao processo de recomendação automática de conteúdos relacionados. Para isso, é utilizado o módulo do sistema denominado RecommendationsBuilder, que foi implementado de modo a receber como entrada uma lista de OAs e fornecer como saída outra lista, contendo um conjunto de OAs recomendados como conteúdos relacionados aos OAs da lista de entrada. Este processo consiste, então, na geração de um conjunto de recomendações, para cada OA da lista de entrada, de modo que cada recomendação aponte outro OA presente no repositório e indique o tipo de relação que estabelece com o OA ao qual está sendo recomendado. A Figura 9 ilustra os processo executados pelo módulo RecommendationsBuilder.

Iterando sobre a lista de entrada, cada um dos OAs listados é recuperado a partir do repositório. Dentre os metadados anotados em cada OA, nas etapas anteriores, se encontram as diversas associações geradas a partir de seus termos e conceitos mais relevantes, com base na estrutura da ontologia de domínio. Assim, para cada associação encontrada, as relações que a compõem são analisadas e as classes de termos para as quais apontam como seu alcance são identificadas. Dessa forma, têmse, por meio destas relações, arcos que conectam o documento a diversas outras classes de conceitos, a partir de cada um de seus termos mais relevantes. Assim, para cada relação presente em cada uma das associações geradas, para cada um dos termos mais relevantes, em cada um dos OAs da lista de entrada, é realizada uma busca no repositório de conteúdos por outros OAs cujos termos mais relevantes pertençam à classe de alcance do termo, apontada na relação em análise. Em cada OA encontrado seu VT é analisado. Caso contenha o termo fonte da associação em análise, este OA é então recomendado como conteúdo relacionado ao OA principal e o tipo de relação é qualificada como sendo do tipo descrito na associação do termo fonte. As recomendações realizadas são listadas para que o usuário possa selecionar aquelas que deseja manter. Em seguida, são armazenadas para que possam ser utilizadas na etapa de agregação de conteúdos. A Figura 10 ilustra parte do arquivo que registra as recomendações geradas para os respectivos OAs.

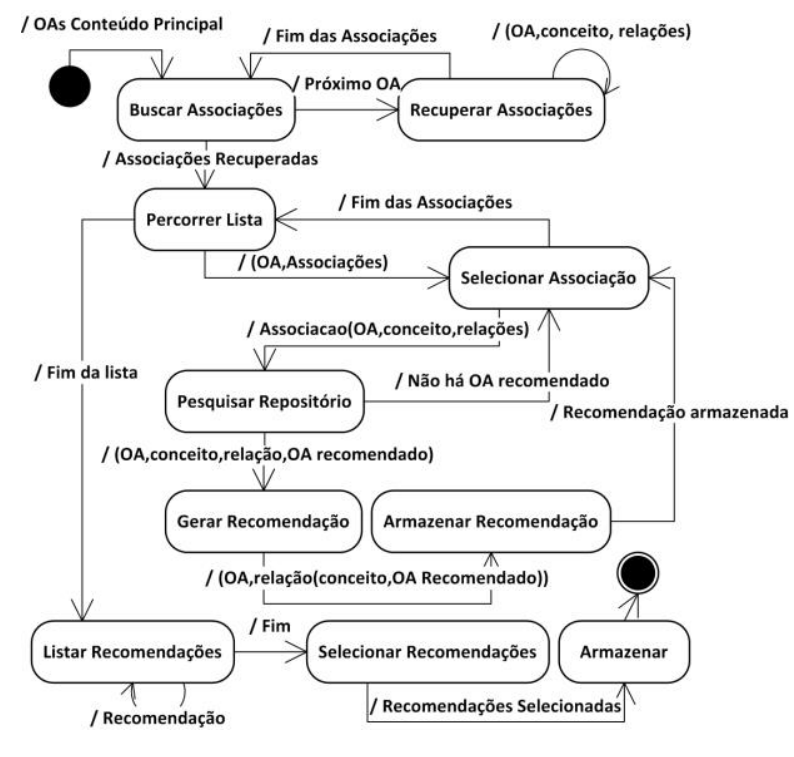

Figura 9 - Processo de recomendação automática 


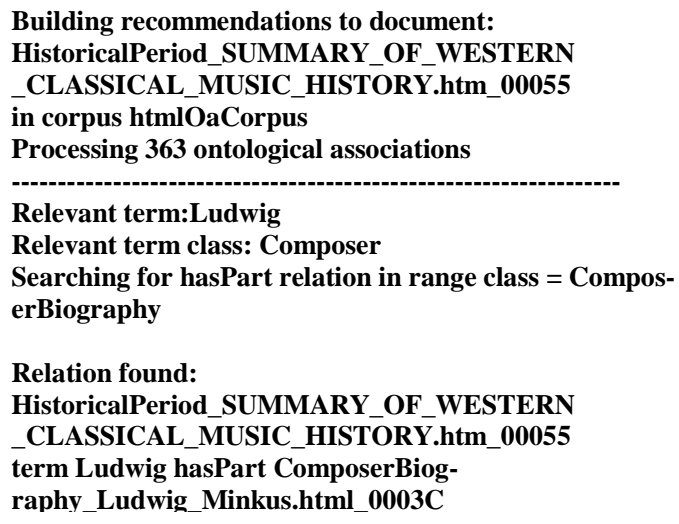

Relation found:

HistoricalPeriod_SUMMARY_OF_WESTERN

_CLASSICAL_MUSIC_HISTORY.htm_00055

term Ludwig hasPart ComposerBiog-

raphy_Ludwig_Minkus.html_0003C

Figura 10 - Parte do arquivo de registro das recomendações geradas

\subsection{Agregação de Conteúdos}

Nesta etapa, uma lista de OAs é gerada a partir do conteúdo principal e dada como entrada para o processo de agregação do conteúdo. Para cada OA, são recuperados os metadados relativos ao seu título e à sua localização no repositório. Após a agregação de todo o conteúdo principal, a lista de OAs é, então, processada para agregação do conteúdo relacionado. Para cada OA do conteúdo principal são, então, recuperadas as recomendações anteriormente geradas para cada um de seus conceitos relevantes. As recomendações são analisadas e os OAs recomendados também têm seu título e localização no repositório recuperados, passando a estar associados ao OA principal, de modo que o OA relativo à recomendação é associado por meio do devido atributo da categoria relation, conforme o tipo de associação estabelecida. Ao final, todos os OAs são copiados do repositório de conteúdos e encapsulados, compondo, finalmente, o pacote de conteúdos SCORM resultante de todo o processo. A Figura 11 apresenta o processo de agregação de conteú-

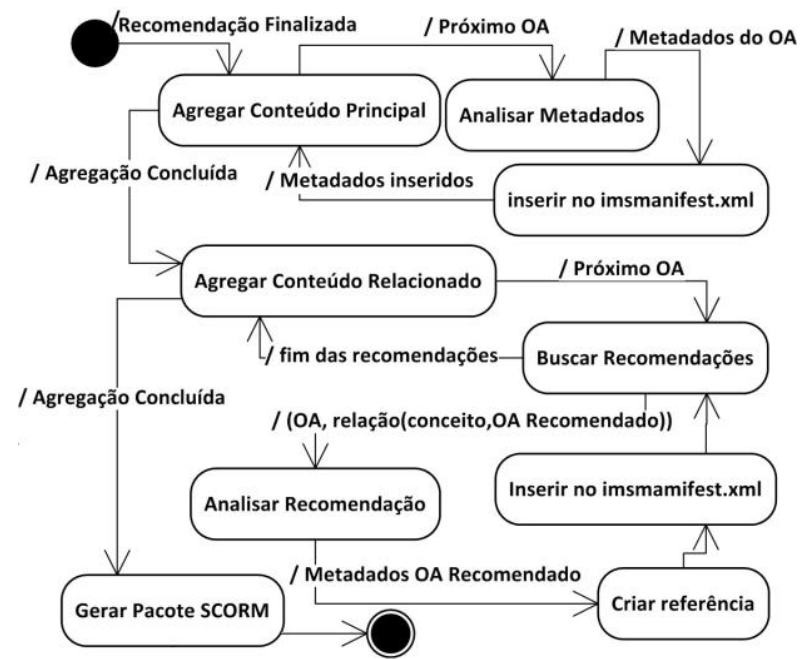

dos e geração do pacote SCORM.

Figura 11 - Processo de agregação de conteúdos

\section{Testes e Resultados Alcançados}

Como parte deste trabalho foi organizado um repositório de OAs, composto de 8.967 documentos, cujos conteúdos estão compreendidos dentro do domínio da música erudita. Para a realização dos testes e avaliação dos resultados, foi necessária a execução de uma etapa de anotação manual de metadados e indicação de termos relevantes, como será descrito a seguir. Sendo assim, devido à dificuldade inerente à realização manual destes processos, uma amostragem foi gerada a partir do total de OAs presentes no repositório, mantendo-se a mesma proporção no percentual de documentos para cada categoria. Os documentos foram selecionados de forma automática e aleatoriamente, conforme a Tabela 1. Dentre os 111 documentos obtidos, 10 se limitavam a apresentar o nome de um compositor e a discografia com suas obras. Estes não foram analisados, resultando ao final em 101 documentos.

\begin{tabular}{|l|l|l|}
\hline \multicolumn{1}{|c|}{ Classificação } & \multicolumn{1}{|c|}{$\begin{array}{c}\mathbf{N}^{\circ} \\
\text { Documentos }\end{array}$} & Amostragem \\
\hline $\begin{array}{l}\text { Biografias de Compo- } \\
\text { sitores }\end{array}$ & 37 & 33,3 \\
\hline Períodos Históricos & 2 & 1,8 \\
\hline Termos de Glossário & 14 & 12,6 \\
\hline Obras Musicais & 58 & 52,3 \\
\hline Total de documentos: & 111 & 100,0 \\
\hline
\end{tabular}

Tabela 1 - Composição da Amostragem inicial

Quatro profissionais da Educação aceitaram o convite para contribuir com esta pesquisa. A cada colaboradora foi solicitado que realizasse a anotação manual de todos os 101 documentos da amostragem final, indicando também os termos que julgassem mais relevantes, dentre os termos anotados, a cada documento, a partir dos quais deveriam ser recomendados outros documentos que estivessem a eles relacionados, no intuito de estender ou complementar seu conteúdo. Apenas três colaboradoras concluíram a atividade dentro do prazo previsto para trinta dias, resultando em 303 documentos anotados. Foram utilizados para análise os dois resultados que apresentaram maior número de anotações, cujas colaboradoras serão identificadas como A e B. Cada documento foi analisado e teve as anotações manualmente computadas. Os termos indicados como mais relevantes, por cada colaboradora, foram por elas listados em uma planilha, para cada documento. Os resultados obtidos são apresentados e comparados na Tabela 2. Nela estão presentes a contagem total de termos manualmente anotados sobre a amostragem, por ambas colaboradoras, quantos destes são relevantes ao domínio e qual foi a acurácia total alcançada no processo de anotação manual. Também são apresentados os resultados 
gerados por cada uma das colaboradoras individualmente, obtendo-se o percentual de acurácia para cada uma delas. As médias de anotações por classe de documento também compõem esta tabela, permitindo uma análise mais refinada do comportamento das colaboradoras quanto ao processo de anotação, como será discutido a seguir. Outra informação importante, que consta na Tabela 2 , é a contagem final de termos indicados como mais relevantes sobre a amostragem, tanto por cada uma das colaboradoras quanto pela soma dos resultados. A importância desta informação reside no fato de que a base para as relações entre os documentos, segundo a metodologia proposta, se encontra no vetor de termos relevantes gerado para cada documento.

\begin{tabular}{|c|c|c|c|c|c|c|c|c|}
\hline \multicolumn{3}{|c|}{ Anotações Sobre a Amostragem } & \multicolumn{2}{|c|}{ Col. A } & \multicolumn{2}{|c|}{ Col. B } & \multicolumn{2}{|c|}{ Acurácia } \\
\hline Total & Relevantes & Acurácia & Total & Rel. & Total & Rel. & Col. A & Col. B \\
\hline 1892 & 1231 & 65,06 & 749 & 492 & 1143 & 739 & $65,69 \%$ & $64,65 \%$ \\
\hline \multirow{4}{*}{$\begin{array}{l}\text { Média de } \\
\text { Anot. / do- } \\
\text { cumento/ } \\
\text { classe }\end{array}$} & \multicolumn{2}{|c|}{ Biog. de Compositores } & 8,43 & 4,50 & 20,07 & 15,50 & $53,39 \%$ & $77,22 \%$ \\
\hline & \multicolumn{2}{|c|}{ Períodos Históricos } & 156,0 & 117,0 & 123,0 & 117,0 & $75,00 \%$ & $95,12 \%$ \\
\hline & \multicolumn{2}{|l|}{ Glossário } & 7,14 & 5,93 & 5,50 & 5,43 & $83,00 \%$ & $98,70 \%$ \\
\hline & \multicolumn{2}{|c|}{ Obras Musicais } & 4,36 & 2,81 & 6,46 & 1,90 & $64,59 \%$ & $29,40 \%$ \\
\hline \multicolumn{3}{|c|}{ Indicação de termos mais relevantes } & \multicolumn{2}{|c|}{287 termos } & \multicolumn{2}{|c|}{191 termos } & \multicolumn{2}{|c|}{478 total } \\
\hline
\end{tabular}

Tabela 2 - Resultados da anotação manual

A Tabela 3 indica o número de resultados coincidentes, que consiste no conjunto interseção dos termos anotados por ambas as colaboradoras, para cada classe de documentos, assim como dos termos que foram indicados, também por ambas, como mais relevantes sobre a amostragem. Estes dados permitem uma análise das possíveis variações no padrão de anotação adotado por diferentes atores. No caso deste trabalho, entre as colaboradoras A e B.

\begin{tabular}{|c|c|c|}
\hline $\begin{array}{c}\text { Classes de docu- } \\
\text { mentos }\end{array}$ & $\begin{array}{c}\text { Anotações } \\
\text { coincidentes }\end{array}$ & $\begin{array}{l}\text { Termos mais } \\
\text { relevantes }\end{array}$ \\
\hline $\begin{array}{l}\text { Biografia de } \\
\text { Compositores }\end{array}$ & 53 & \multirow{5}{*}{$\begin{array}{c}53 \\
\text { coincidên- } \\
\text { cias de } \\
\text { termos indi- } \\
\text { cados. }\end{array}$} \\
\hline $\begin{array}{l}\text { Períodos Histó- } \\
\text { ricos }\end{array}$ & 41 & \\
\hline Glossário & 41 & \\
\hline Obras Musicais & 13 & \\
\hline Total & 148 & \\
\hline
\end{tabular}

Tabela 3 - Contagem de resultados coincidentes por conjunto de documentos

Foram considerados não relevantes os termos e conceitos anotados, pela colaboradoras, que não se referiam ao domínio da música erudita, tendo como referência principal a ontologia de domínio, e aqueles que se referiam a informações genéricas, tais como "ganhador de quatro prêmios", "nascido em Paris", dentre outros. Essas anotações foram recorrentes no caso da Colaboradora A. Estes termos também não foram computados na contagem dos termos indicados como mais relevantes para cada documento. Durante a análise do material, percebe-se a dificuldade em se manter a coerência no processo de anotação manual. Ao anotar documentos pertencentes à mesma classe, com o mesmo formato e padrão para disponibilização das informações, ora um determinado conjunto de termos foi marcado como relevante, ora não, pela mesma colaboradora. Por exemplo, nos textos relativos às obras musicais, a Colaboradora $\mathrm{A}$ manteve o padrão de anotação, marcando sempre o autor, o tipo de obra, a data e local de apresentação, com pouquíssima variação, não anotando elementos presentes no texto da sinopse, o que talvez possa ser consequência da atividade cansativa e repetitiva que consiste na anotação manual de metadados. A Colaboradora B, por sua vez, ora inseria anotações na sinopse da obra, ora na ficha técnica, ora nos nomes dos personagens das óperas, sendo difícil identificar o critério adotado. Além disso, a quantidade de anotações da Colaboradora B diminuiu consideravelmente entre os primeiros e últimos documentos anotados. Nos documentos maiores, ela indicou como os termos mais relevantes apenas aqueles presentes na primeira página.

Concluído o trabalho por parte das colaboradoras, assim como a análise do material por elas produzido, a mesma amostragem foi submetida ao protótipo do Sistema de Recomendação e Agregação de Conteúdos Relacionados, implementado neste trabalho para avaliação da metodologia proposta, executando-se todos os processos, da anotação à recomendação. Os resultados da anotação automática são apresentados na Tabela 4 . 


\begin{tabular}{|c|l|c|c|c|}
\hline \multicolumn{2}{|c|}{ Anotações Sobre a Amostragem } & Total & Verdadeiros Positivos & Acurácia \\
\hline \multicolumn{2}{|c|}{ Termos Anotados: } & $\mathbf{6 2 2 8}$ & $\mathbf{4 9 8 8}$ & $\mathbf{8 0 , 0 9 \%}$ \\
\hline \multirow{2}{*}{$\begin{array}{c}\text { Média de } \\
\text { Anotações } \\
\text { /documento/cl } \\
\text { asse }\end{array}$} & Biografia de Compositores & 84,93 & 71,14 & $83,77 \%$ \\
\cline { 2 - 5 } & Períodos Históricos & 1213,00 & 1083,00 & $89,28 \%$ \\
\cline { 2 - 5 } & Glossário & 23,71 & 23,07 & $97,29 \%$ \\
\cline { 2 - 5 } & Obras Musicais & 39,07 & 26,95 & $69,98 \%$ \\
\hline
\end{tabular}

Tabela 4 - Resultados da anotação automática.

Sobre a amostragem utilizada foram geradas 3508 associações ontológicas sobre os 101 OAs. Para testar especificamente o processo de recomendação de conteúdos relacionados, foi dado como entrada o OA da amostragem que contém o maior conteúdo, pertence à classe Períodos Históricos e totaliza 363 associações. As relações estabelecidas por estas associações foram analisadas pelo sistema e geraram um conjunto de 12 recomendações finais para este documento sobre os 101 OAs contidos na amostragem. Estas recomendações estão divididas da seguinte forma: um OA como isrequiredby; sete como isreferencedby e quatro como haspart. As 12 recomendações geradas automaticamente estavam corretas e são apresentadas no Quadro 1. A Figura 12 ilustra uma das recomendações.

Para realização dos testes, foi utilizada uma máquina com processador Intel Core I3 com $2.27 \mathrm{GHz}$ por núcleo, 4 GB de RAM e utilizando o Microsoft Windows 7. Os processos de carregamento, armazenamento, anotação automática e geração de associações sobre a ontologia, para toda a amostragem, foram executados em 1 minuto, 43 segundos e 2 décimos de segundo. O processo de geração de recomendações foi executado em 5 décimos de segundo.

\begin{tabular}{|l|l|l|l|}
\hline \multicolumn{2}{|c|}{ HistoricalPeriod_SUMMARY_OF_WESTERN_CLASSICAL_MUSIC_HISTORY.htm } \\
\hline isrequiredby & Music_Theor_Online_Music_of_the_20th_Century.htm \\
\hline isreferencedby & $\begin{array}{l}\text { ComposerBiography_Victor_Herbert.html, ComposerBiography_Colin_Matthews.html, , } \\
\text { ComposerBiography_Antonin_Dvorak.html, ComposerBiography_Henry_Purcell.html, Compo- } \\
\text { graphy_Ludwig_Minkus.html. }\end{array}$ \\
\hline haspart & $\begin{array}{l}\text { GlossaryTermDefinition_Recorder.htm, Charles_Wakefield_Cadman.htm, Gus- } \\
\text { tav_Mahler.html, Charles_Wakefield_Cadman.htm }\end{array}$
\end{tabular}

Quadro 1 - Resultado da recomendação automática

\section{Relevant term: classical music \\ Relevant term class: Classical \\ Relevant term superclass $=$ HistoricalPeriod \\ HistoricalPeriod_SUMMARY_OF_WESTERN_CLASSICAL_MUSIC_HISTORY.htm_00055 term classical music isRequiredBy HistoricalPeriod_Music_Theor_Online_Music_of_the_20th_Century.htm_00054}

Figura 12 - Parte do arquivo gerado para as recomendações finais

Percebe-se uma diferença nos parâmetros de análise, entre os resultados automático e manual, sendo que no segundo não há ocorrência de termos não relevantes, devido à consistência da base de conhecimento e ao fato de que apenas termos nela presentes são anotados. Todavia, a atenção, neste caso, se volta para a geração de falsos positivos. Estas ocorrências se devem a problemas difíceis da recuperação da informação e que fogem ao escopo deste trabalho, tais como o tratamento de homônimos e de duplicação, cuja maior ocorrência se deve aos nomes de compositores e termos de ocorrência ampla, facilmente presentes em contextos fora da área de domínio, como nos casos de "time" e "scale", que cons- tam no glossário como "tempo musical" e "escala musical", mas foram responsáveis por parte dos falsos positivos. Outro conjunto de falsos positivos foi gerado para compositores cujos primeiros ou segundos nomes são monossilábicos e podem ser interpretados como stop words ou pertencentes a outras classes gramaticais que não sejam a dos nomes próprios. Os nomes $\mathrm{He}$, She, An são exemplos de ocorrências como estas, ficando a anotação correta a cargo do nome completo. Os OAs da classe Obras Musicais foram os que mais apresentaram falsos positivos devido à grande presença de nomes de personagens, que muitas vezes foram anotados como primeiros nomes de compositores. Ao contrário, os OAs 
pertencentes ao glossário foram os que apresentaram o menor número de falsos positivos, pois consistem de textos com descrições técnicas, cujos termos são específicos e dificilmente incorrem em homônimos ou apresentam duplicação. No caso específico dos compositores, a divisão do dicionário em uma lista para nomes completos, uma para primeiros nomes e outra para segundos nomes fez com que, em alguns momentos, nomes tais como Michael Tilson Thomas tivessem mais de uma anotação, sendo "Michael" anotado como segundo nome de um compositor e também como primeiro nome, "Tilson Thomas" como segundo nome e "Michael Tilson Thomas" como nome completo de compositor, o que gerou um falso positivo. Outro exemplo de falso positivo com homônimos ocorreu com Bernard Haitink, que é um maestro e teve Bernard anotado como o primeiro nome de um compositor. O mesmo observado para "York", que é o primeiro nome de um compositor, mas foi assim anotado quando ocorreu em New York. Outra ocorrência de falsos positivos ligados a nomes de compositores se deve àqueles que possuem segundos nomes iguais aos nomes de países. Na biografia de Kosku Yamada, Berlin aparece tanto como a cidade alemã quanto como o compositor Berlin Musikhochschule e todas as vezes foi marcado como primeiro nome de compositor. Por isso, gerou falsos positivos nos casos em que se tratava da cidade de Berlim. Autores com nomes de meses do ano, como April, também geram falsos positivos, pois na língua inglesa os nomes dos meses são grafados com a primeira maiúscula. Todavia, o nome do autor ainda será anotado corretamente quando ocorrer por completo, pelo primeiro nome ou pelo segundo nome, quando diferentes deste caso. Outro caso interessante e não trivial ocorre quando um compositor possui um dos nomes cujo termo pertence a outra classe de termos. Por exemplo, Ballet. Ballet é um estilo de composição ou trabalho musical, mas há um compositor que possui Ballet como segundo nome. Neste caso, o termo recebe as duas anotações, uma delas sendo falso positivo. Casas de espetáculo com nomes de compositores ou personalidades homônimas de compositores também geraram falsos positivos.

Todavia, é interessante atentar para o fato de que estes falsos positivos, em sua maioria, eram eliminados ou recebiam ponderação muito baixa no processo de classificação hierárquica, conforme os parâmetros descritos na Seção 3.1, não sendo considerados para as etapas de criação de associações e recomendação de conteúdos relacionados. Este fator importante é claramente percebido para os nomes de compositores onde primeiros nomes geraram falsos positivos. Como os compositores são citados na maior parte do texto por seus nomes completos ou por seus segundos nomes, estes obtiveram um fator de relevância muito maior que seus primeiros nomes, fazendo com que estes ficassem, na maioria das vezes, fora dos processos de associação ontológica e recomendação automática que é o objetivo principal deste trabalho e não o processo de anotação. Ainda assim, para os falsos positivos que cheguem a compor associações e entrem no processo de recomendação, na maioria das vezes os documentos recomendados a partir deles recebem, no passo final, um score menor do que aqueles que foram recomendados para verdadeiros positivos. Isso demonstra como a metodologia proposta atua como esperado a partir da execução do conjunto de seus processos, fornecendo mecanismos capazes de minimizar o número de falsos positivos na recomendação de conteúdos relacionados. Ainda assim, aqueles falsos positivos que acabem por serem considerados podem impactar ao final de todo o processo, gerando recomendações não relevantes e, por isso, o último filtro para as recomendações geradas, antes da agregação do conteúdo, é realizado manualmente pelo responsável por sua composição.

A utilização de uma única lista com os nomes completos poderia se apresentar como possível solução para o problema das diversas marcações sobre nomes de compositores, tais como Michal Tilson Thomas, mas criaria um problema com falsos negativos, quando os autores fossem referenciados apenas pelo segundo nome, o que é muito comum na literatura. A utilização de duas listas no dicionário, uma com nomes completos e outra com segundos nomes, além da resolução de homônimos e duplicação, talvez seja uma solução plausível. Para o problema dos compositores com nomes de países, utilizar-se de uma solução trivial, tal como inserir uma listagem de países, pareceria algo plausível à primeira vista, mas poderia gerar um grande número de marcações não relevantes, número maior do que os falsos positivos gerados pelos nomes dos compositores, entendendo-se que "Países" não consiste em uma classe de termos relevantes ao domínio da música. Seriam geradas duas anotações para o nome tendo-se, assim, um verdadeiro positivo e um falso positivo, além de suas anotações para o caso de um país, tendo-se novamente um verdadeiro positivo e um falso positivo. Uma listagem de nomes de meses, para os autores que os têm em seus primeiros nomes, consiste na mesma questão levantada para o nome dos países. No caso de homônimos entre compositores, uma possível abordagem seria subdividir a classificação de compositores, agrupando-os por períodos históricos ou gêneros musicais e criando-se heurísticas com base nessa relação. De todo modo, a solução para homônimo é um caso não trivial. Para recomendação de conteúdos relacionados, por exemplo, identificar exatamente a qual dos compositores de mesmo nome um dado texto se refere talvez exija a análise de uma combinação de outros elementos do texto, para se tentar associar, por exemplo, o nome do compositor ao período histórico ou às obras musicais, aos quais o texto se refira. 
Durante a análise do processo de anotação manual, identificou-se que locais importantes, como casas de ópera, teatros e renomadas escolas de música foram anotados de forma recorrente pelas colaboradoras, mas não estão representados na ontologia. Da mesma forma, percebe-se que nos textos, muitos termos e conceitos relevantes ao domínio não são anotados por estarem em outro idioma, tais como francês, alemão e italiano, como é comum no domínio da música. Nestes casos, têm-se sempre falsos negativos para o processo de anotação automática, o que incorrerá, no caso da metodologia proposta, na falta de recomendação para tais termos.

Os termos que são iguais, mas que são identificados por anotações diferentes, não têm suas frequências absolutas somadas, na função de relevância proposta, sendo interpretados individualmente, como estão anotados. Por exemplo, "ERNESTO LECUONA", "Ernesto Lecuona", "Ernesto" e "Lecuona", foram anotados corretamente no documento sobre este autor, mas como termos independentes e assim foram ponderados. Se sua ponderação fosse somada e eles aparecessem como um único termo no vetor de relevância para o documento, provavelmente traria associado ao nome do autor um valor muito maior de relevância. Todavia, percebe-se que mesmo anotados separadamente, os termos aparecem nos primeiros lugares na classificação hierárquica por relevância, sendo "Lecuona" com relevância igual a 6.0, "Ernesto" com 4.5 e "Ernesto Lecuona" com 3.0. Isso garante que o autor seja considerado em primeiro lugar na fase de recomendação de conteúdos.

\section{Conclusões e Trabalhos Futuros}

Este trabalho teve como objetivo a proposição de uma metodologia para recomendação automática de OAs relacionados, em conformidade com o SCORM. Assim, possibilitou o estabelecimento de relações entre OAs, utilizando a categoria de metadados relation, tal como definida pelo padrão e sem a necessidade de utilização ou desenvolvimento de SGAs específicos para interpretar tais metadados. Além disso, percebe-se que as diversas abordagens presentes na literatura se pautam em um processo de pesquisa por conteúdos relacionados que é realizado pelo usuário, quando a metodologia proposta neste trabalho adota outra perspectiva, segundo a qual os OAs são recomendados como conteúdos relacionados a um dado conteúdo de referência, previamente selecionado, visando à construção de uma unidade de aprendizagem.

Foi elaborada e construída, como parte deste trabalho, uma base de conhecimento de domínio, contendo um extenso dicionário de termos e uma ontologia capaz de apresentar uma conceituação da área de domínio utilizada e o estabelecimento de relações entre as diversas classes de conceitos. Esta base de conhecimento foi efetivamente empregada pelo protótipo de um Sistema de Recomendação e Agregação de Conteúdos Relacionados, também desenvolvido nesta pesquisa e que implementa a metodologia proposta. Os seguintes módulos do sistema foram implementados e atenderam a cada uma das etapas da metodologia: AssignerRelevance, para anotação automática de metadados e classificação hierárquica dos conceitos relevantes; AssociationsBuilder, para geração de associações entre os conceitos relevantes e a ontologia de domínio; RecommendationsBuilder, para geração de recomendações de conteúdos relacionados, a partir das associações preestabelecidas. O plugin ANNIE foi utilizado apenas para o processo de anotação automática de metadados, empregando a base de conhecimento.

Com base na análise dos testes realizados, observa-se que a metodologia proposta nesta pesquisa é viável e produz os resultados esperados, com boa precisão e eficiência, além de superiores àqueles alcançados unicamente por seres humanos. Pode ser aplicada a diferentes áreas do conhecimento, para a composição de conteúdos didático-pedagógicos, sendo necessário apenas $\mathrm{o}$ emprego de uma base de conhecimento de domínio relacionada à área desejada. Diante disso, verifica-se que a recomendação automática de OAs relacionados pode auxiliar os desenvolvedores de conteúdo para e-Learning na composição de OAs em conformidade com o SCORM, reduzindo o tempo e o esforço necessários ao desenvolvimento e agregação de conteúdos relacionados e facilitando o seu reaproveitamento.

Há diversas possibilidades de ampliação desta pesquisa e melhorias nos resultados obtidos. Devido ao fato de que a metodologia proposta é fortemente dependente da base de conhecimento, falsos negativos podem ocorrer para os termos e conceitos que não estão nela presentes. Reduzir o número de falsos positivos no processo de geração e anotação de metadados é de extrema importância, pois estes podem impactar no final do processo, gerando falsos positivos também nos documentos recomendados, pois falsos positivos que passem à fase de geração de associações podem influenciar a recomendação. Isso demonstra que a acurácia do processo de recomendação está relacionada à acurácia da fase de anotação e classificação hierárquica. Possíveis abordagens para redução destas ocorrências consistem na resolução dos problemas de recuperação da informação, anteriormente levantados, e na avaliação de diferentes métricas na função de cálculo de relevância, sendo que a primeira abordagem procuraria reduzir diretamente o número de anotações sobre falsos positivos e a segunda procuraria reduzir o número de falsos positivos anotados que passariam à fase de geração de associações. A identificação de novas classes na ontologia pode ampliar a cobertura para a recomendação de conteúdos relacionados sob a área de 
domínio.

Desse modo, este trabalho de pesquisa cumpriu com os objetivos propostos, apresentando uma metodologia eficiente para recomendação de OAs relacionados, em conformidade com o SCORM. O sistema implementado traduz a metodologia e apresenta bons resultados quanto aos processos de anotação automática de metadados, associação ontológica para identificação de relações e recomendação automática de conteúdos relacionados. Contudo, há muito que se pesquisar e avançar na melhoria destes processos. Seja por meio da experimentação e comparação de diferentes métricas para o cálculo de relevância, seja revisando, ampliando e modificando a ontologia de domínio, acrescentando-se o tratamento para múltiplos idiomas, aplicando-se estratégias para redução de falsos positivos e resolução de homônimos, ou propondo melhorias na própria metodologia.

\section{Referências}

[1] ADVANCED DISTRIBUTED LEARNING. SCORM 2004 4th Edition - Content Aggregation Model [CAM]. Disponível em: <http://www.adlnet.gov>. Acesso em: 11 jul. 2013.

[2] ADVANCED DISTRIBUTED LEARNING. SCORM 2004 4th Edition - Run-Time Environment (RTE). Disponível em: <http://www.adlnet.gov>. Acesso em: 11 jul. 2013.

[3] ADVANCED DISTRIBUTED LEARNING. SCORM 2004 4th Edition - Sequencing and Navigation [SN. Disponível em: <http://www.adlnet.gov>. Acesso em: 11 jul. 2013.

[4] V. S. Baghela, S. P. Tripathi. Text Mining Approaches To Extract Interesting Association Rules from Text Documents. International Journal of Computer Science Issues, 9(3): 545-552, 2012.

[5] K. Bontcheva, V. Tablan, D. Maynard, e al. Evolving GATE to meet new challenges in language engineering. Natural Language Engineering, 10(3): 349-373, 2004.

[6] Y. Chen, Y. Liu, W. Ho. A Text Mining Approach to Assist the General Public in the Retrieval of Legal Documents. Journal of the American Society for Information Science and Technology, 64(2): 280-290, 2013.

[7] H. Cunningham, D. Maynard, K. Bontcheva, et al. Developing Language Processing Components with GATE Version 7 (a User Guide). University of Sheffield Department of Computer Science, 2012.

[8] L. F .H. Edvardsen, I. T. Solvberg, T. Aalberg, et al.
Using automatic metadata generation to reduce the knowledge and time requirements for making SCORM learning objects. Digital Ecosystems and Technologies. 3rd IEEE International Conference, Istanbul, páginas 253-258, 2009.

[9] M. Engelhardt, A. Hildebrand, D. Lange, et al. Reasoning about eLearning Multimedia Objects. International Workshop on Semantic WEB Annotations for Multimedia, Edinburgh, 2006.

[10] Z. Guo, H. Jin. Reference Metadata Extraction from Scientific Papers. Cluster and Grid Computing LabServices Computing Technology and System LabHuazhong University of Science and Technology. 12th International Conference on Parallel and Distributed Computing, Applications and Technologies, Gwangju, páginas 45-49, 2011.

[11] A. Hernández et al. Convirtiendo el contenido de archivos en objetos de aprendizaje. In Anais do $20^{\circ} \mathrm{Sim}$ pósio Brasileiro de Informática na Educação, Florianópolis., 2009.

[12] Z. Guo, H. Jin. A Rule-Based Framework of Metadata Extraction from Scientific Papers. Proceedings of the 2011 10th International Symposium on Distributed Computing and Applications to Business, Engineering and Science, Washington, páginas 400-404, 2011.

[13] T. Huynh, K. Hoang. GATE framework based metadata extraction from scientific papers. 2010 International Conference on Education and Management Technology, Cairo, páginas 188 - 191, 2010.

[14] M. Lipinski, K. Yao, C. Breitinger, et al. Evaluation of header metadata extraction approaches and tools for scientific PDF documents. Proceedings of the 13th ACM/IEEE-CS joint conference on Digital libraries (JCDL '13), New York, páginas 385-386, 2013.

[15] E. J. Lu, C. Hsieh. A relation metadata extension for SCORM Content Aggregation Model. Computer Standards \& Interfaces. 31(5): 1028-1035, 2009.

[16] E. J. LU, G. Horng, C. Yu, et al. Extended relation metadata for SCORM-based learning content management systems. Educational Technology \& Society. 13(1): 220-235, 2010.

[17] M. Margaritopolous, A. Manitsaris, I. Mavridis. On the Identification of Inference Rules for Automatic Metadata Generation. Proceedings of the 2nd International Conference on Metadata and Semantics Research (CD-ROM), 2007.

[18] A. Maratea, A. Petrosino, M. Manzo. Automatic Generation of SCORM Compliant Metadata for Portable Document Format Files. International Conference on Computer Systems and Technologies - CompSysTech'12, 
New York, páginas 360-67, 2012.

[19] D. Maynard. Benchmarking ontology-based annotation tools for the semantic web. In Proc. of 6th International Conference on Language Resources and Evaluation (LREC), Marrakech, 2008.

[20] A. Nauerz, F. Bakalov, B. König-Ries, et al. Personalized recommendation of related content based on automatic metadata extraction. In Proceedings of the 2008 conference of the center for advanced studies on collaborative research: meeting of minds, New York, 2008.

[21] R. P. Díaz-Redondo, A. F. Vilas, J. J. P. Arias. Educateca: A Web 2.0 Approach to e-Learning with SCORM. Software Services for e-World -IFIP. Intelligent Systems Reference Library, 32(1):195 - 207, 2012.

[22] M. Rey-López, R. P. Díaz-Redondo, A. FernándezVilas, et al. An extension to the ADL SCORM standard to support adaptivity: The t-learning case-study. Computer Standards \& Interfaces, 31(2): 309-318, 2009.

[23] D. Roy, S. Sarkar, S. Ghose. Automatic extraction of pedagogic metadata from learning content. International Journal of Artificial Intelligence in Education, 18(2): 97-118, 2008.

[24] J. Su, S. Tseng, C. Chen, et al. Constructing SCORM compliant course based on High-Level Petri Nets. Computer Standards \& Interfaces, 28(3): 336-355, 2006.

[25] P. K. Bhowmick, et al. A framework for manual ontology engineering for management of learning material repository. International Journal of Computer Science and Applications, 7(2): 30-51, 2010.

[26] M. G. V. A. Ferreira, M. Araújo. Educação a Distância e Web Semântica: Modelagem Ontológica de Materiais e Objetos de Aprendizagem para a Plataforma CoL. Tese de Doutorado, Universidade de São Paulo, set 2003. 